\title{
Comparing Impact of STATCOM and SSSC on the Performance of Digital Distance Relay
}

\author{
Amir Ghorbani ${ }^{\dagger}$ \\ ${ }^{\dagger}$ Department of Electrical Engineering, Abhar Branch, Islamic Azad University, Abhar, Iran
}

\begin{abstract}
In this paper the impact of a SSSC and a STATCOM on the impedance calculated by a distance relay is investigated. Both analytical analysis and simulations are provided. The STATCOM/SSSC control systems are modeled in detail. It is demonstrated that a SSSC has a greater impact on the calculated impedance by an A-G distance relay element. Several scenarios are considered in the simulations like the impact of the fault conditions, the compensator settings, the power system conditions and so on. All the simulations are carried out in MATLAB/Simulink with detailed models of the SSSC and the STATCOM.
\end{abstract}

Key Words: Digital distance relay, STATic synchronous COMpensator (STATCOM), Static Synchronous Series Compensator (SSSC)

\section{INTRODUCTION}

By using an appropriate method for the shunt compensation of reactive power, the transmittable steady state power is increased and the voltage profile along the transmission line is controlled. The STATCOM is one example of a shunt compensation device of the Flexible AC Transmission Systems (FACTS) family. It is a static synchronous generator which is used for shunt compensation of reactive power, and its inductive or capacitive current can be controlled independently of the system AC voltage. The STATCOM produces a set of three-phase voltages which are controllable with the AC power system frequency. Each output voltage couples and synchronizes with its counterpart voltage in an AC system using a relating reactance which is provided by the coupling generator's phase leakage inductance. The Static Synchronous Series Compensator (SSSC) is a series device of the FACTS family that uses power electronics to control the power flow and to improve the power oscillation damping on power grids. When an SSSC injects an alternating voltage leading the line current, it emulates an inductive reactance in series with the transmission line causing the power flow as well as the line current to decrease as the level of compensation increases. At this time the SSSC is considered to operate in inductive mode.

When an SSSC injects an alternating voltage lagging the line current, it emulates a capacitive reactance in series with the transmission line causing the power flow as well as the line current to increase as the level of compensation increases. At this time the SSSC is considered to be operating in a capacitive

Manuscript received Dec. 27, 2010; revised Aug. 11, 2011

Recommended for publication by Associate Editor Kyo-Beum Lee.

$\dagger$ Corresponding Author: amirghorbani.elec@gmail.com

Tel: +98-914-343-4074, Abhar Branch, Islamic Azad University

Dept. of Electrical Eng., Abhar Branch, Islamic Azad University, Iran. mode. Therefore, the SSSC can apply rapid changes in system parameters such as the line impedance and the line currents [1].

Distance relays are used to protect transmission lines. They can estimate the place of a fault by calculating its impedance. Voltage and current values are used to calculate the impedance [2], [3]. When a single phase-to-ground fault occurs, the system voltage decreases and the shunt compensator (STAT$\mathrm{COM}$ ) tries to cope with this situation by injecting reactive power and capacitive current into the network in order to return the voltage to its reference value $\left(V_{R e f}\right)$. As a result of these actions the impedance calculated by a distance relay is changed by the shunt compensator.

Research in this field can be categorized into three different categories based on how the compensators are installed onto a network. The first group of papers is about the FACTS devices which are installed onto a network in series [4]-[7]. The second group is concerned with investigating the impact of shunt FACTS device on the performance of distance relays [8], [9]. The third group deals with the FACTS devices which contain both shunt and series sections [10], [11]. In all of these investigations, the authors show that the presence of FACTS compensators in a fault loop cause the calculated apparent impedance by the distance relay revolved. The study reported in [8] considered the performance of the distance relay in a transmission system with a STATCOM. The authors show that the STATCOM operation increases the R/X ratio of the apparent impedance under all operating conditions. In [9], a study on the performance of distance protection relays applied to protect shunt FACTS compensated transmission lines, and the effect of two types of shunt FACTS devices, SVC and STATCOM, are presented.

Detailed models of the STATCOM and the SSSC are 
described in this paper. The STATCOM and the SSSC use a square-wave, 48-pulse Voltage Source Converter (VSC) and interconnection transformers for harmonic neutralization. The outline of this paper is as follows: Section II describes the STATCOM, the SSSC and the transmission system models. Analytical analysis and relay modelling are presented in section III and simulation results are presented in section IV.

\section{System UNDER STUdy, SSSC AND STATCOM MODELS}

\section{A. System under study model}

A single line diagram of the system under study together with equivalent circuits of a STATCOM and a SSSC are shown in Fig. 1. The considered power system contains two 300 $\mathrm{km}, 500 \mathrm{kV}$ transmission lines. The parameters of the power system are listed in the appendix.

\section{B. STATCOM model}

In modeling the \pm 200 Mvar STATCOM installed in the middle of the transmission line, four three-level 48-pulse inverters coupled with four phase shifting transformers, introducing phase shift of \pm 7.5 degrees, are used [1], [10]. The STATCOM consists of two series-connected $3000 \mu \mathrm{F}$ capacitors which act as a variable DC voltage source.

The control system of the STATCOM is shown in Fig. 2. The values and angles for the output voltages are calculated from $I_{q R e f}$. In this control system, the controller inputs are: the three-phase AC voltage $V_{a b c}($ Prim), the STATCOM output current $I_{a b c}(s h)$, the reference reactive current $I_{q R e f}$, the reference voltage $V_{R e f}$ (if the main objective is controlling the STATCOM output voltage), and the DC reference voltage $V_{d c R e f}$, which is used to provide the active power that should be absorbed from the AC system by the converter to supply the internal losses. The STATCOM output currents are composed of two factors: the reactive $\left(I_{q}\right)$ and the active $\left(I_{d}\right)$ currents. The reactive current is compared with the reference reactive current $I_{q R e f}$ and the $\alpha$ angle is obtained by appropriately amplifying the error. This angle defines the replacement phase essential between the converter output voltage and the system $\mathrm{AC}$ voltage to charge (or discharge) the storage capacitor until it reaches the required DC voltage level. Therefore $\alpha+\theta$ is obtained by summing the $\alpha$ and $\theta$ angles, which provides the synchronizing signal of the converter, which in turn provides the reference reactive current. It should be noted that $\theta$ is the AC system three-phase voltage $\left(V_{a b c}\right.$ where the STATCOM is installed) angle calculated by a phase lock loop (PLL) [1], [12].

\section{SSSC model}

The modeled SSSC in this paper is based on 48-pulsed converters which cause realistic improvements in power quality and reduced harmonics. Fig. 3 shows a control block diagram of an SSSC. An instantaneous three-phase set of line voltages, at $B l$ is used to calculate the reference angle $\theta=\omega t$ and is decomposed into its real or direct component, $V_{d}$ and its reactive or quadrature component, $V_{q}$. Then the amplitude,

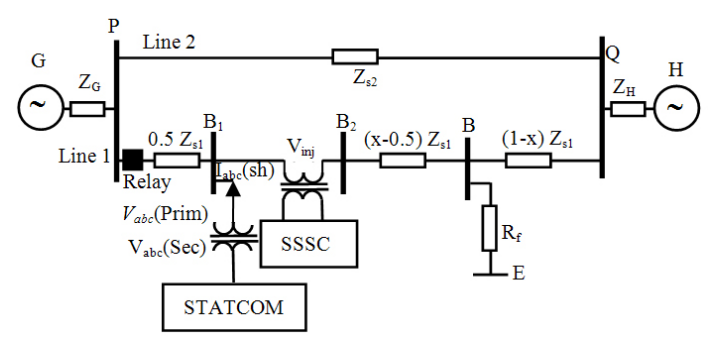

(a)

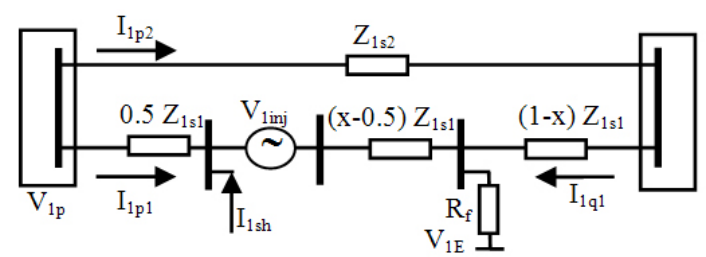

(b)

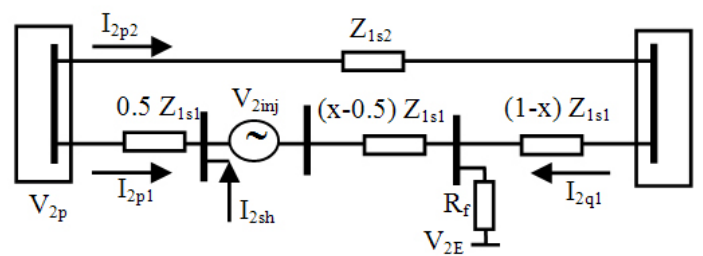

(c)

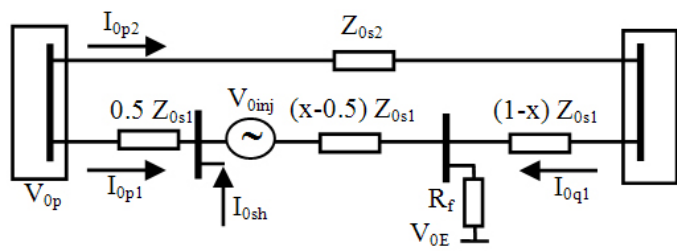

(d)

Fig. 1. (a) Single line diagram of the system under study. (b) Positive sequence network. (c) Negative sequence network. (d) Zero sequence network.

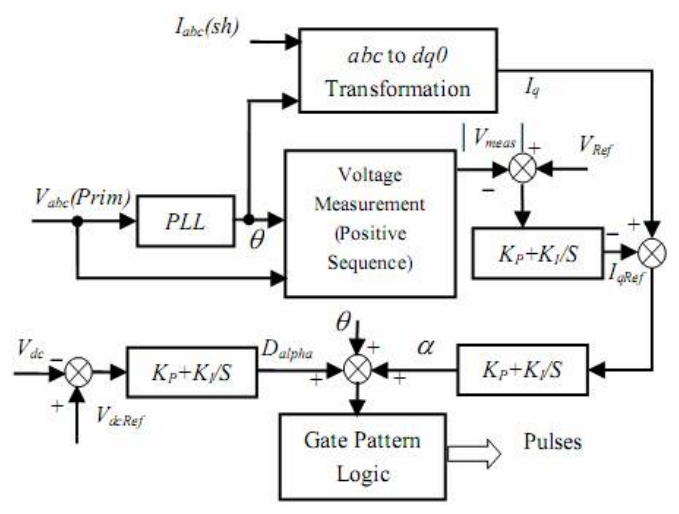

Fig. 2. STATCOM control system. 


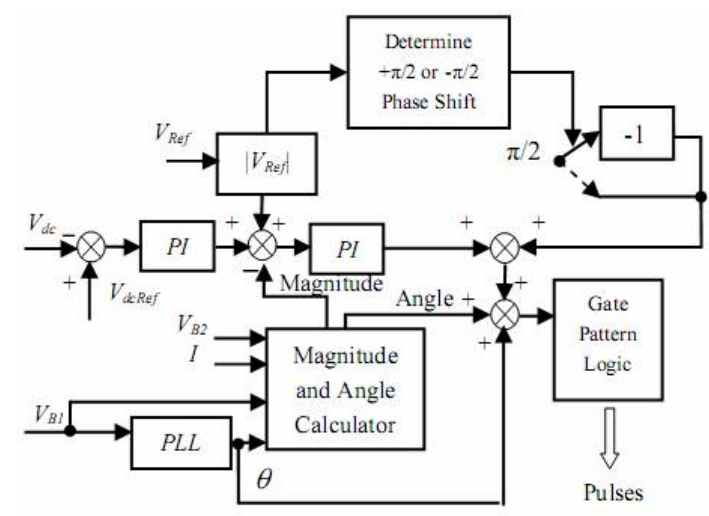

Fig. 3. SSSC control system.

$V_{i n j}$ is calculated. The compensating voltage, $V_{i n j}$ is controlled by a simple closed loop. The absolute value of the reference, $V_{R e f}$ is compared to the measured magnitude of the injected voltage, $V_{i n j}$ and the amplified difference (error) is passed through a PI controller (Error Amplifier). It is then added, as a correction angle $\Delta \alpha$, to the synchronizing signal $\theta=\omega t$. An instantaneous three-phase set of measured line currents, $I$ is decomposed into its real or direct component, $I_{d}$ and its reactive or quadrature component, $I_{q}$. Then the relative angle, of the line current with respect to the phase-lock-loop angle, are calculated. The phase shifter is operated from the output of the polarity detector, which determines whether the reference, $V_{R e f}$ is positive (capacitive) or negative (inductive). Depending on the polarity of $\Delta \alpha$, the angle $\theta$ and consequently the converter gate drive signals will be advanced or retarded. As a result, the compensating voltage, $V_{i n j}$ will be shifted with respect to the prevailing line current from its original $+\pi / 2$ or $-\pi / 2$ phase position. This phase shift will cause the converter to absorb real power from the ac system for the $\mathrm{dc}$ capacitor or, vice versa to supply it to the ac system from the dc capacitor. As a result, the voltage of the dc capacitor will increase or decrease, causing a corresponding change in the magnitude of the compensating voltage. Once the desired magnitude of $V_{i n j}$ is reached, the substantially quadrature relationship between the line current and the compensating voltage gets reestablished with only a small remaining, steady angular difference necessary to absorb power from the ac system to replenish the operating losses of the converter [1], [12].

\section{Analytical AnAlysis}

A single line diagram of the system model considered for analysis is shown in Fig.1. The shunt compensator is installed in the middle of transmission line 1. The STATCOM acts like a controllable current source that has instantaneous responses to changes in the system conditions. Fig. 1 shows an SSSC connected in series with transmission line 1 between $B 1$ and $B 2$. The SSSC is modeled by a series connected voltage source. Distance relays have been installed in the Bus $P$ to protect transmission line 1 . The positive, negative and zero sequence networks of the system under study are shown in Fig. 1. In this system it is supposed that a fault has occurred in the B location. The following definitions have been attended for convenience:

$V_{0 p}, V_{1 p}$, and $V_{2 p}$ : are the sequence phase voltages at the relay location of Bus $P$.

$I_{0 p 1}, I_{1 p 1}$, and $I_{2 p 1}$ : are the sequence phase currents through line 1 at the relay location of Bus $P$.

$I_{0 p 2}, I_{1 p 2}$, and $I_{2 p 2}$ : are the sequence phase currents through line 2 at the relay location of Bus $P$.

$I_{0 q 1}, I_{1 q 1}$, and $I_{2 q 1}$ : are the sequence phase currents through line 2 of Bus $Q$.

$V_{0 i n j}, V_{1 i n j}$, and $V_{2 i n j}$ : are the sequence phase voltages injected or absorbed by a SSSC.

$I_{0 s h}, I_{1 s h}, I_{2 s h}$ : are the sequence phase currents injected or absorbed by a STATCOM.

$V_{0 E}, V_{1 E}, V_{2 E}$ : are the sequence phase voltages at fault location $B$.

$Z_{0 s 1}, Z_{1 s 1}, Z_{2 s 1}$ : are the sequence impedances of line 1 .

$Z_{0 s 2}, Z_{1 s 2}, Z_{2 s 2}$ : are the sequence impedances of line 2 .

$R_{f}:$ is the fault resistance.

$X$ : is the fault per-unit distance from the relay location.

In regard to the positive sequence network, for lines 1 and 2 of Bus $P$, the following equations can be derived:

$$
\begin{aligned}
& V_{1 p}=x Z_{1 s 1} I_{1 p 1}+(x-0.5) Z_{1 s 1} I_{1 s h} \\
& +R_{f}\left(I_{1 p 1}+I_{1 s h}+I_{1 q 1}\right)+V_{1 E}+V_{1 i n j} \\
& \quad V_{1 p}=Z_{1 s 2} I_{1 p 2}+(1-x) Z_{1 s 1} I_{1 q 1} \\
& \quad+R_{f}\left(I_{1 p 1}+I_{1 s h}+I_{1 q 1}\right)+V_{1 E} .
\end{aligned}
$$

By eliminating the term $V_{1 E}$ from (1) and (2), the following equation is obtained:

$$
\begin{aligned}
& I_{1 q 1}=\frac{x}{(1-x)} I_{1 p 1}+\frac{(x-0.5)}{(1-x)} I_{1 s h}-\frac{k_{1}}{(1-x)} I_{1 p 2} \\
& +\frac{V_{1 i n j}}{(1-x) Z_{1 s 1}}
\end{aligned}
$$

Where:

$$
k_{1}=Z_{1 s 2} / Z_{1 s 1} .
$$

By substituting (3), into (1), the following equation is obtained:

$$
\begin{aligned}
& V_{1 p}=x Z_{1 s 1} I_{1 p 1}+(x-0.5) Z_{1 s 1} I_{1 s h}+R_{f}\left(\frac{1}{(1-x)} I_{1 p 1}\right. \\
& \left.+\frac{0.5}{(1-x)} I_{1 s h}-\frac{k_{1}}{(1-x)} I_{1 p 2}\right)+V_{1 E}+\frac{A V_{1 i n j}}{(1-x) Z_{1 s 1}}
\end{aligned}
$$

Where:

$$
(1-x) Z_{1 s 1}+R_{f} \text {. }
$$

In the same way, in terms of negative and zero sequence networks, they are obtained by:

$$
\begin{aligned}
& V_{2 p}=x Z_{1 s 1} I_{2 p 1}+(x-0.5) Z_{1 s 1} I_{2 s h}+R_{f}\left(\frac{1}{(1-x)} I_{2 p 1}\right. \\
& \left.+\frac{0.5}{(1-x)} I_{2 s h}-\frac{k_{1}}{(1-x)} I_{2 p 2}\right)+V_{2 E}+\frac{A V_{2 i n j}}{(1-x) Z_{1 s 1}} \\
& V_{0 p}=x Z_{0 s 1} I_{0 p 1}+(x-0.5) Z_{0 s 1} I_{0 s h}+R_{f}\left(\frac{1}{(1-x)} I_{0 p 1}\right. \\
& \left.+\frac{0.5}{(1-x)} I_{0 s h}-\frac{k_{0}}{(1-x)} I_{0 p 2}\right)+V_{0 E}+\frac{A V_{0 i n j}}{(1-x) Z_{1 s 1}}
\end{aligned}
$$

Where:

$$
k_{0}=Z_{0 s 2} / Z_{0 s 1}
$$




\section{A. Single phase to ground fault}

For a single phase-to-ground fault, the boundary condition is:

$$
V_{0 E}+V_{1 E}+V_{2 E}=0 .
$$

It is derived from (5), (7), (8) and (10) that:

$$
\begin{aligned}
& V_{L-G}=x\left[Z_{1 s 1} I_{p 1}+\left(Z_{0 s 1}-Z_{1 s 1}\right) I_{0 p 1}\right]+ \\
& \frac{R_{f}}{(1-x)}\left[I_{p 1}-K_{1} I_{p 2}+\left(K_{1}-K_{0}\right) I_{0 p 2}\right]+\Delta V_{L-G}
\end{aligned}
$$

Where:

$$
\begin{gathered}
V_{0 p 1}+V_{1 p 1}+V_{2 p 1}=V_{L-G} \\
V_{0 i n j}+V_{1 i n j}+V_{2 i n j}=V_{i n j} \\
I_{0 s h}+I_{1 s h}+I_{2 s h}=I_{s h} \\
I_{0 p 1}+I_{1 p 1}+I_{2 p 1}=I_{p 1} \\
I_{0 p 2}+I_{1 p 2}+I_{2 p 2}=I_{p 2}
\end{gathered}
$$

And

$$
\begin{aligned}
& \Delta V_{L-G}=(x-0.5) Z_{1 s 1} I_{s h}+(x-.05)\left(Z_{0 s 1}-Z_{1 s 1}\right) I_{0 s h} \\
& +\frac{R_{f}}{(1-x)} I_{s h}+\frac{A}{(1-x) Z_{1 s 1}}\left(V_{i n j}+V_{0 i n j}\left(1 / Z_{0 s 1}-1\right)\right) .
\end{aligned}
$$

For a single phase-to-ground fault, like an A-G fault, the calculated impedance by the distance relay is obtained by the following equation:

$$
Z_{L-G}=\frac{V_{L-G}}{I_{p 1}+\left[\left(Z_{0 s 1}-Z_{1 s 1}\right) / Z_{1 s 1}\right] I_{0 p 1}}=\frac{V_{L-G}}{I_{L-G}} .
$$

It is derived from (11) and (18) such that:

$$
\begin{aligned}
& Z_{L-G}=x Z_{1 s 1}+\frac{R_{f}}{(1-x) I_{L \cdot G}}\left(I_{p 1}-k_{1} I_{p 2}\right. \\
& \left.+\left(k_{1}-k_{0}\right) I_{0 p 2}\right)+\Delta Z_{L-G} .
\end{aligned}
$$

In (19), the $\Delta Z_{L-G}$ value depends on the presence compensator and it is equal to:

$$
\begin{aligned}
& \Delta Z_{L-G}=(x-0.5) Z_{1 s 1} \frac{I_{s h}}{I_{L-G}}+ \\
& (x-0.5)\left(Z_{0 s 1}-Z_{1 s 1}\right) \frac{I_{0 s h}}{I_{L-G}}+R_{f} \frac{0.5}{(1-x)} \frac{I_{s h}}{I_{L-G}}+ \\
& \frac{1}{I_{L-G}}\left(V_{i n j}+V_{0 i n j}\left(\frac{Z_{1 s 1}}{Z_{0 s 1}}-1\right)\right) .
\end{aligned}
$$

As can be seen in (20), the presence compensator in a fault loop effects the calculated impedance by the relay. When the compensator is not in a fault loop, its effect on the impedance $Z_{L-G}$ is only by $R_{f}$.

\section{B. Phase to phase fault}

For a phase-to-phase fault like an A-B fault, the boundary condition is:

$$
V_{1 E}=a V_{2 E}
$$

Where:

$$
a=-0.5+j 0.886 .
$$

It is derived from (5), (7) and (21) such that:

$$
\begin{aligned}
& V_{1 p}-a V_{2 p}=x Z_{1 s 1}\left(I_{1 p 1}-a I_{2 p 1}\right)+ \\
& (x-0.5) Z_{1 s 1}\left(I_{1 s h}-a I_{2 s h}\right)+\left(V_{1 i n j}-a V_{2 i n j}\right)+ \\
& \frac{R_{f}}{(1-x)}\left(\left(I_{1 p 1}-a I_{2 p 1}\right)+0.5\left(I_{1 s h}-a I_{2 s h}\right)+\right. \\
& \left.k_{1}\left(a I_{2 p 2}-I_{1 p 2}\right)+\left(V_{1 i n j}-a V_{2 i n j}\right) / Z_{1 s 1}\right) .
\end{aligned}
$$

For an A-B fault, the calculated impedance by the distance relay is obtained by following equation:

$$
Z_{L-L}=\frac{V_{1 p}-a V_{2 p}}{I_{1 p 1}-a I_{2 p 1}}=\frac{V_{1 p}-a V_{2 p}}{I_{L-L}} .
$$

By substituting (23) into (24), $Z_{L-L}$ will be:

$$
\begin{aligned}
& Z_{L-L}=x Z_{1 s 1}+\frac{R_{f}}{(1-x) I_{L-L}}\left(\left(I_{1 p 1}-a I_{2 p 1}\right)+\right. \\
& \left.k_{1}\left(a I_{2 p 2}-I_{1 p 2}\right)\right)+\Delta Z_{L-L} .
\end{aligned}
$$

In the above equation, $\Delta Z_{L-L}$ depends on the presence of a shunt compensator and it is equal to:

$$
\begin{aligned}
& \Delta Z_{L-L}=(x-0.5) Z_{1 s 1} \frac{\left(I_{1 s h}-a I_{2 s h}\right)}{I_{L-L}}+\frac{\left(V_{1 i n j}-a V_{2 i n j}\right)}{I_{L-L}} \\
& \frac{R_{f}}{(1-x) I_{L-L}}\left(0.5\left(I_{1 s h}-a I_{2 s h}\right)+\frac{V_{1 i n j}-a V_{2 i n j}}{Z_{1 s 1}}\right) .
\end{aligned}
$$

In the above equation, $R_{f}$ is the fault resistance between two phases. According to (26) for $R_{f}=0$, the SSSC/STACOM impact is due to the negative and positive sequence voltage/current differences.

A procedure for designing a fault impedance estimation algorithm for distance protection is discussed in this section. A digital distance relaying algorithm is proposed that uses the phasor estimates, the sequence components of the phasors and a fault classification scheme, before calculating the fault distance. Its basic modules are shown Fig. 4. The measured voltages and currents at the relay point are sampled at 64 samples per cycle [2], [3].

\section{Simulation Results}

In this paper a 48-pulsed voltage source converter (VSC) is used to model the STATCOM and the SSSC. For example the output of the 48-pulsed converter in the STATCOM and the SSSC are shown in Fig. 5 and Fig. 6, respectively.

\section{A. Single phase to ground fault}

The AC system voltages are normally balanced and therefore the compensator normally controls all three phases of their output current together. With an unbalanced system, like when an A-G fault occurs, due to the internally generated negative sequence converter voltage, the STATCOM provides substantially balanced, capacitive compensating currents [1]. The amplitudes of all three phase output voltages for the SSSC start to increase after fault occurrences. This is due the nature of the SSSC control system which is set to control all three phase output voltages simultaneously. As a result, after an A-G fault all three phases are compensated.

The calculated apparent impedance by the A-G relay element for the same A-G fault has been shown in Fig. 7. As 


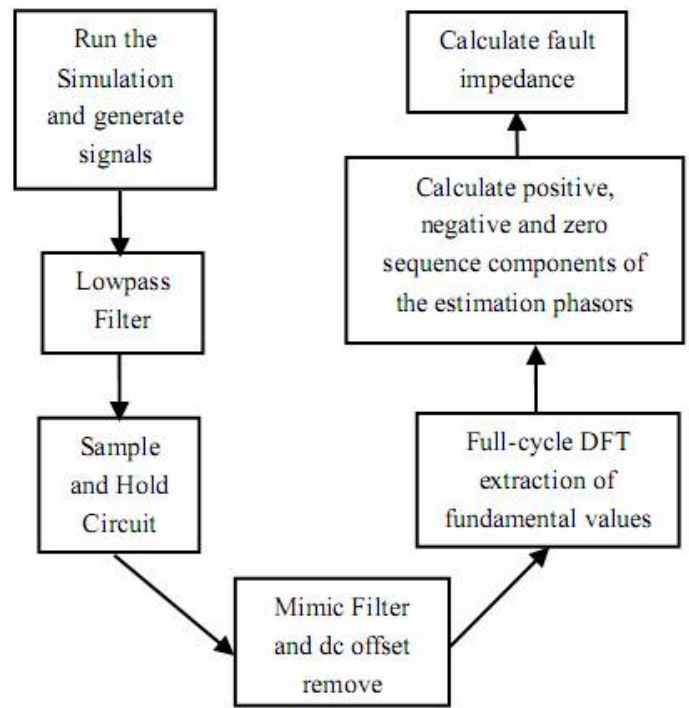

Fig. 4. Basic modules of distance relaying.

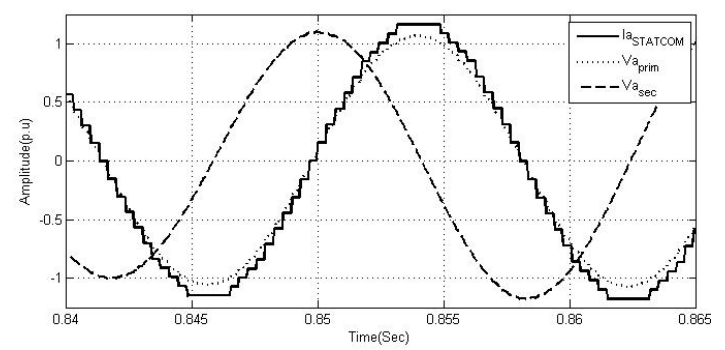

Fig. 5. 48-pulse converter output voltage $\left(V_{\text {asec }}\right)$, AC system voltage $\left(V_{\text {aprim }}\right)$, and output current of STATCOM $\left(I_{\text {aSTACOM }}\right)$.

shown in Fig. 7, when the compensator is not used, the relay recognizes the impedance value correctly and then enters zone 1. When an SSSC is used, the relay is overreached and fails to act because the impedance is considered beyond its real place. The presence of a STATCOM in a fault loop does not have a greater effect on the calculated apparent impedance by relay.

According to the analytical analysis, the STATCOM effect in the impedance $Z_{L-G}$, is achieved (20). Its imaginary and real parts were simulated for the same A-G fault, as is shown in Fig. 8. By comparing the results shown in Fig. 7 and Fig. 8 , it is clear that there is complete consistency between the simulation results and the analytical analysis. The effects of the negative, positive and zero sequences of the injected voltage by the SSSC are shown in Fig. 9. As can be seen in the figure, the zero element of the injected voltage has the dominant effect(equation 20).

\section{B. The effect of STATCOM and SSSC settings}

In this part as in the pervious part, it is supposed that an A-G fault has occurred in transmission line 1.

Depending on the system conditions, the STATCOM may have different settings. When a fault transition occurs in a system, the system voltage during the fault decreases significantly and therefore, the system voltage is below $V_{R e f}$ during the fault. The STATCOM has to produce reactive power to compensate the voltage, independent of its setting. The simulation results for three different STATCOM settings,

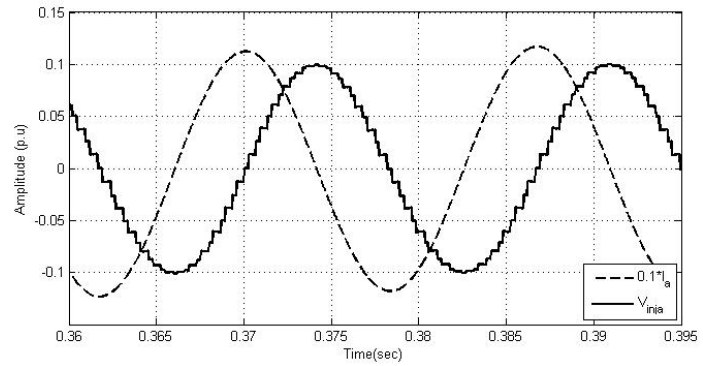

Fig. 6. 48-pulse converter output voltage and line current.

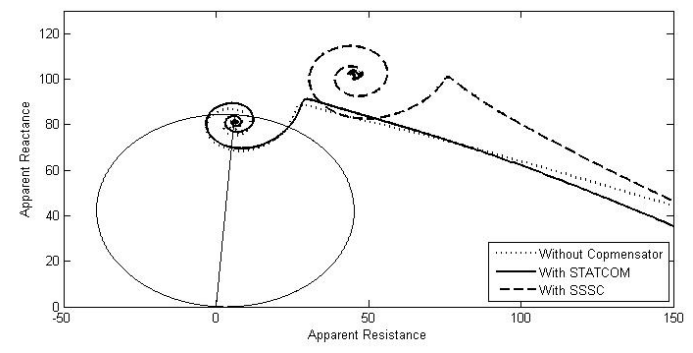

Fig. 7. Apparent impedance calculated by A-G relay element.

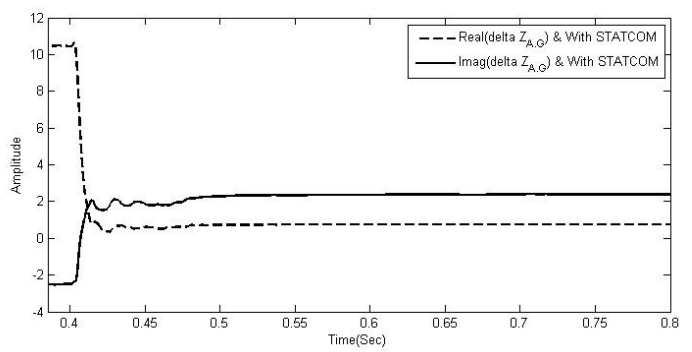

Fig. 8. Imaginary and real parts of $\Delta Z_{L-G}$ for an A-G fault accrued in $0.4 \mathrm{~s}$ at a fault distance $225 \mathrm{~km}$ from the relaying point.

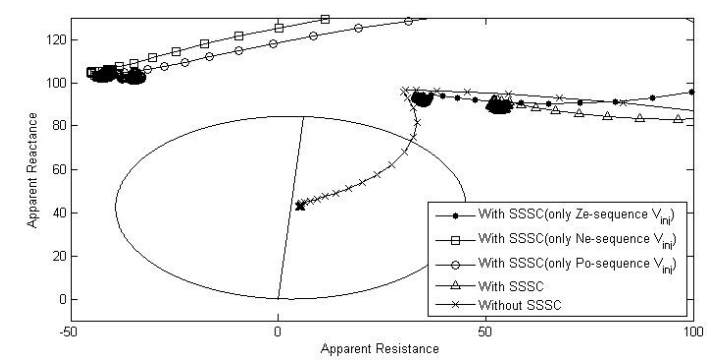

Fig. 9. Impedance seen by the relay (A-G fault and with/without SSSC (fault distance $=150 \mathrm{~km}$ ).

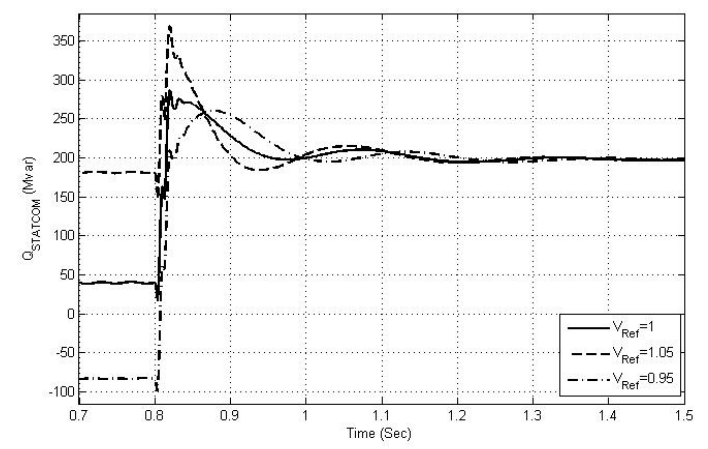

Fig. 10. STATCOM reactive power injection with different STATCOM setting. 


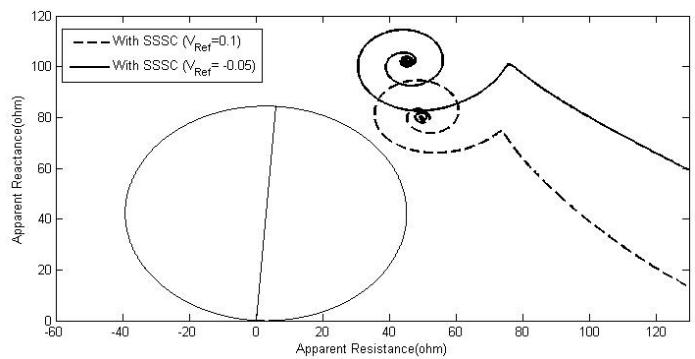

Fig. 11. Apparent impedance calculated by the A-G measuring unit of the relay for an A-G fault.

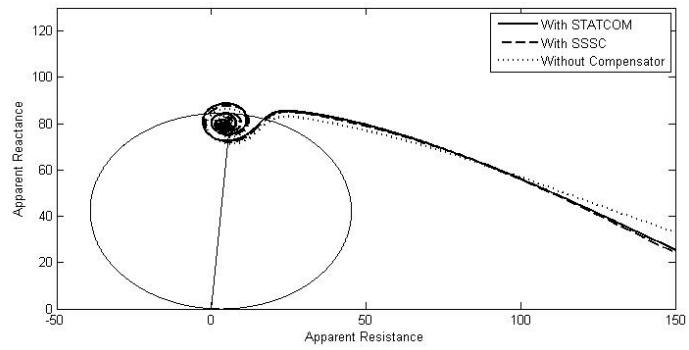

Fig. 12. Apparent impedance calculated by A-B relay element for an A-B fault at the distance $225 \mathrm{~km}$ from the relaying point.

where $V_{R e f}=0.95,1,1.07$ p.u., for an A-G fault occurring in a place $150 \mathrm{~km}$ away from the R1 relay, are shown in Fig. 10. It can be seen in Fig. 10 that, after the A-G fault, the STATCOM produces the same reactive power under all three conditions. Therefore, the STATCOM setting does not have a significant impact on the calculated impedance because it injects a unique amount of reactive power in all settings.

The calculated apparent impedance by the phase to ground fault (A-G) measuring unit is shown in Fig. 11 for the aforementioned fault (A-G fault) with different SSSC settings. As shown in the Fig. 11, the SSSC has increased the calculated amount of impedance (under-reach of the relay) in both cases.

\section{Phase to phase fault}

For an A-B fault at a $225 \mathrm{~km}$ distance from a relay point the calculated impedance by the A-B relay element is shown in Fig. 12.

As can be seen from Fig. 12, the presence compensator in the fault loop does not have a greater effect on the calculated impedance by the A-B relay element.

\section{System short circuit level (SCL)}

Fig. 13 and Fig. 14 show the apparent impedance calculated by the A-G relay element for an A-G fault at a distance of 225 $\mathrm{km}$ from the relaying point and different system SCLs with the presence of a SSSC and a STATCOM, respectively. As can be seen in Fig. 13, the impact of a SSSC on the apparent impedance is significant for weak systems and this impact is greater on the apparent reactance. This is because the fault currents for weak systems are weaker in comparison with strong systems. Therefore in system with a small SCL, the SSSC injected voltages are significant in comparison with the fault currents.

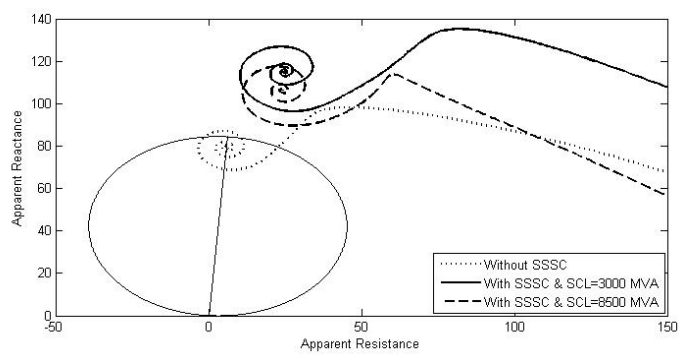

Fig. 13. Apparent impedance calculated by A-G relay element.

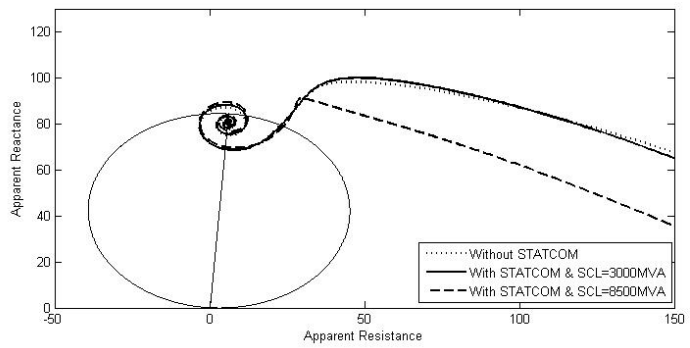

Fig. 14. Apparent impedance calculated by A-G relay element.

\section{CONCLUSIONS}

It is shown that the impact of a SSSC on the apparent impedance is significant only for single phase faults due to the zero sequence component of the injected voltage of a SSSC.

This study analyzes the performance of a STATCOM when several practical factors are considered in the model, including the multilevel converter model, and the model of the practical control systems. The modeling of a STATCOM by cascaded multilevel converters, i.e., 48-pulse (three levels) source converters, is preferable. Otherwise, the injected currents deviate a great deal from sinusoids, and harmonics are presented which may affect the operation of a distance relay.

\section{APPENDIX}

The $300 \mathrm{~km}, 500 \mathrm{kV}$ transmission lines has the following data:

$Z_{1 s 1}=Z_{1 s 2}=0.0255+j 0.3520 \Omega / \mathrm{km}$

$Z_{0 s 1}=Z_{0 s 2}=0.3864+j 1.5556 \Omega / \mathrm{km}$

Parameters for sources at $\mathrm{G}$ and $\mathrm{H}$ :

Short Circuit Level $(\mathrm{SCL})=8500 \mathrm{MVA}$

System frequency $=60 \mathrm{~Hz}$

Load angle between sources $=30^{\circ}$

Amplitude ratio between source voltages at $\mathrm{G}$ and $\mathrm{H}=1.07$

\section{REFERENCES}

[1] N. G. Hingorani and L. Gyugyi, Understanding FACTS Concepts and Technology of Flexible AC Transmission Systems, New York: IEEE Press, 2000.

[2] Y. Liao and S. Elangovan, "Digital distance relaying algorithm for first-zone protection for parallel transmission lines," IEE Proc.-Gener. Transm. Distrib. Vol, 145, No. 5, pp. 531-536, Sep. 1998.

[3] D. L. Waikar, S. Elangovan, and A. C. Liew, "Fault impedance estimation algorithm for digital distance relaying," IEEE Trans. Power Del., Vol. 9, No. 3, pp. 1375-1383, Jul. 1994.

[4] M. Khederzadeh and T. S. Sidhu, "Impact of TCSC on the protection of transmission lines," IEEE Trans. Power Del., Vol. 21, No. 1, pp. 80-87, Jan. 2006.

[5] M. Khederzadeh, A. Ghorbani, and A. Salemnia, "Impact of SSSC on the digital distance relay," IEEE/PES General Meeting, 2009. 
[6] P. K. Dash, A. K. Pradhan, G. Panda, and A. C. Liew, "Digital protection of power transmission lines in the presence of series connected FACTS devise," in Proc. IEEE Power Engineering Soc. Winter Meeting, Vol. 3, pp. 1967-1972, 2000.

[7] A. Kazemi, S. Jamali, and H. shateri, "Effect of SSSC on distance relay tripping characteristic," in Proc. First International Power and Energy Conference PECon, pp. 623-628, 2006.

[8] El-Arroudi, G. Joos, and D. T. McGillis, "Operation of impedance protection relays with the STATCOM," IEEE Trans. Power Del., Vol. 17, No. 2, pp. 381-387, Apr. 2002.

[9] T. S. Sidhu, R. K. Varma, P. K. Gangadharan, F. A. Albasri and G. R. Ortiz, "Performance of distance relays on shunt-FACTS compensated transmission lines," IEEE Trans. Power Del., Vol. 20, No. 3, pp. 1837 1845, Jul. 2005.

[10] X. Zhou, H. Wang, R. K. Aggarwal, and P. Beaumont, "Performance evaluation of a distance relay as applied to a transmission system with UPFC,' IEEE Trans. Power Del., Vol. 21, No. 3, pp. 1137-1147, Jul. 2006.
[11] P. K. Dash, A. K. Pradhan, G. Panda, and A. C. Liew, "Adaptive relay setting for flexible AC transmission systems (FACTS)," IEEE Trans. Power Del., Vol. 15, No. 1, pp. 38-43, Jan. 2000.

[12] M. S. El-Moursi and A. M. Sharaf, "Novel controllers for the 48-pulse VSC STATCOM and SSSC for voltage regulation and reactive power compensation," IEEE Trans. Power Syst., Vol. 20, No. 4, pp. 1985-1997, Nov. 2005.

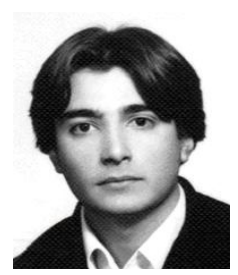

Amir Ghorbani was born in Salmas, Iran, in 1982. He received his B.S. and M.S. in Electrical Engineering from the Azarbaijan University of Tarbiat Moallem, Tabriz, Iran, and the Power \& Water University of Technology, Tehran, Iran, in 2005 and 2008, respectively. $\mathrm{He}$ is currently pursuing his Ph.D. at the Science \& Research Branch, Islamic Azad University, Tehran, Iran. His research interests include flexible AC transmission systems (FACTS) and power system protection. 